\title{
Métodos de prospección arqueológica intensiva en el marco de un proyecto regional: el caso de la comarca de La Serena (Badajoz)
}

\author{
Intensive survey methods in the framework of a regional project: the Serena Region \\ study case
}

Victorino Mayoral Herrera $(*)$
Enrique Cerrillo Cuenca $\left(^{*}\right)$
Sebastián Celestino Pérez $\left(^{*}\right)$

\section{RESUMEN}

El propósito de este trabajo es mostrar la metodología de prospección de superficie empleada en el marco de un proyecto regional sobre la evolución del paisaje en la comarca de La Serena (Badajoz). Se parte de una utilización crítica del concepto de sitio arqueológico y de una valoración del significado de estrategias intensivas de prospección de superficie en el contexto del estudio de la estructuración de los paisajes agrarios preindustriales. Se exponen los planteamientos, diseño y ejecución de los últimos trabajos efectuados. En una primera etapa se realiza una estimación global de la densidad de ítems y se determinan los posibles puntos de interés. Posteriormente se caracterizan cualitativamente las dispersiones detectadas mediante un muestreo aleatorio estratificado. Se pretende de este modo desterrar procedimientos selectivos y poco sistemáticos en la recogida de materiales de superficie, que conducen a notables sesgos en la información. Se destaca el balance alcanzado entre el tiempo y trabajo invertido y la resolución de información obtenida. La puesta en marcha de este método ha revelado su eficacia para caracterizar entidades arqueológicas que frecuentemente no se consideran en los análisis de tipo regional. Se discuten otros factores que interfieren en el reconocimiento de las dispersiones, como el denominado "ruido de fondo".

\footnotetext{
ABSTRACT

The aim of this paper is to show the survey methods developed in the framework of a research project carried

(*) Instituto de Arqueología-Mérida (CSIC-Junta de Extremadura-Consorcio de Mérida). Plaza de España 15. 06800 Mérida. Web: http://www.iam.csic.es/.

Correos electrónicos: vmayoral@iam.csic.es;

ecerrillo@iam.csic.es; scelestino@iam.csic.es.

Recibido: 30-VII-2008; aceptado: 20-I-2009.
}

out in the Serena region (Badajoz Province, Spain). We start from a critical use of the notion of archaeological site and an assessment of the meaning of intensive surface collection in the context of the study of the structure of preindustrial agrarian landscapes. We offer a detailed exposition of the survey planning, data capture and spatial analysis. In a first stage we make a global estimate of density of surface finds, locating possible areas of interest. In a second phase detected dispersions are qualified by systematic sampling. Its main purpose is to dismiss selective procedures leading to remarkable biases in surface record. We emphasize the balance achieved between data resolution and effort invested. This method has shown its effectiveness to characterize archaeological entities often not considered in Peninsular regional projects. Other factors affecting the recognition of sherd scatters are discussed, like the so-called "background noise".

Palabras clave: La Serena; Arqueología de los Paisajes Agrarios; Prospección de Superficie.

Key words: Serena Region; Archaeology of Agrarian Landscapes; Archaeological Surface Survey.

\section{INTRODUCCIÓN (1)}

Como han señalado algunos autores en los últimos años (Blanton 2001; Gillings 2000: 108;

(1) Este trabajo se ha desarrollado en el marco de los siguientes proyectos de investigación: "Prospección arqueológica y SIG entre la Cuenca Media del Guadiana y el valle de La Serena: Estudio comparativo y evolución histórica del territorio", Plan Nacional I+D+I (2004-2007) HUM2004-01070. Investigador Principal: Sebastián Celestino Pérez; "Sistemas de Informa- 
Ruiz Zapatero 2004: 21), una de las principales tendencias en la evolución reciente de los estudios arqueológicos a escala territorial es la creciente focalización del trabajo en pequeñas áreas, que a veces pueden definirse como verdaderas microrregiones. Probablemente la principal motivación para este cambio de escala es el desarrollo de métodos de registro orientados a obtener datos de gran resolución acerca de la distribución de los elementos arqueológicos. Esto es especialmente evidente por lo que respecta a las prospecciones de superficie. A medida que se ha incrementado el conocimiento sobre los factores que influyen en las distribuciones de artefactos y se ha enriquecido la visión sobre las posibles causas de esta complejidad, se ha producido un notable desarrollo en la sofisticación de los sistemas de documentación. Obviamente esto ha supuesto un fuerte aumento del coste material y humano para poder cumplir los objetivos, limitando la capacidad de abarcar extensiones mayores.

La aproximación estadística a la exploración del terreno pretende en buena medida solventar estos problemas, proporcionando estimaciones fiables sobre las pautas de ocupación humana del espacio a partir de técnicas de muestreo. Sin embargo existen problemas relativos a la estructura y escala de determinados procesos políticos, económicos, demográficos, etc., que sólo pueden ser abordados de manera satisfactoria contando con un registro de calidad de espacios de un tamaño significativo. Existe por otro lado otro problema que dificulta el desarrollo fluido del reconocimiento de superficie. Se trata de la discontinuidad que se plantea entre los métodos empleados para el estudio de áreas amplias y los que se utilizan en la prospección intensiva a escala de sitio arqueológico (cuyo incremento es otra de las tendencias actuales en este tipo de estudios).

Detrás de las transformaciones que acabamos de señalar está un cambio aún más profundo que se refiere a la manera de entender la interacción de los grupos humanos entre sí y con su entorno, así como a los medios para aproximarse a esta

\footnotetext{
ción Geográfica aplicados a la investigación y planificación territorial del patrimonio arqueológico de la comarca de La Serena". Junta de Extremadura, PRI 06B098. Investigador principal: Sebastián Celestino Pérez; "Los paisajes agrarios del final de la Protohistoria en el suroeste peninsular: estudio arqueológico del territorio". Proyecto Intramural Especial del CSIC (PIE200710I013). Investigador principal: Victorino Mayoral Herrera.
}

cuestión desde el registro material. La llamada "arqueología de fuera del sitio" cuenta ya con una larga tradición (Foley 1981). Este enfoque asume que es posible identificar con claridad agrupaciones de ítems en superficie susceptibles de ser interpretados como lugares de actividad humana (aunque también como fruto de otros fenómenos no-antrópicos). No obstante, también presta atención al hecho de que numerosos procesos de trabajo y otras pautas de utilización del espacio en torno a los asentamientos dejan una huella material susceptible de ser registrada. Se trata del denominado "ruido de fondo" (Gallant 1986), que ha sido objeto de una gran atención como posible indicador de actividades como el abonado de los campos (Wilkinson 1982, 1989; Hayes 1991). Dicha hipótesis ha sido ampliamente debatida, planteándose numerosos matices y explicaciones alternativas que ponen de manifiesto la gran complejidad de las distribuciones de superficie (Alcock et al. 1994).

Como señala Banning (2002: 20), el modelo de "fuera del sitio" se contrapone conceptual y metodológicamente al de la prospección "sin sitios". Este último tipo de trabajos suele asumir como unidad básica del registro el ítem, planteándose como objetivo no la localización de sitios y su delimitación frente al ruido de fondo, sino el análisis de las variaciones en la presencia de hallazgos de superficie a través del espacio. Esta forma de concebir los datos de superficie puede resultar especialmente operativa para valorar cuestiones tales como la probabilidad de hallazgos y el efecto de diversos factores ambientales (actividad erosiva, formación de suelos, visibilidad de superficie, efecto de las prácticas agrícolas...). Al centrarse en el problema de la distribución, ambos enfoques precisan de sistemas de registro capaces de reflejar, de una forma matizada y con un aceptable nivel de resolución, los cambios en cuanto al tipo, densidad, rodamiento y fragmentación del material. Otra cuestión es la definición de las entidades objeto de registro, que determina el uso de procedimientos más o menos alejados de la tradicional localización y delimitación de los sitios como unidad básica de trabajo. Por nuestra parte consideramos que tiene poco sentido la adopción de posturas radicales. Estimamos en cambio más prudente el diseño de una estrategia que asuma con toda la cautela el concepto de sitio, y que sea capaz de ofrecer una continuidad entre los procedimientos de docu- 
mentación aplicados en éste y los que exigen las distribuciones más débiles y dispersas.

En resumidas cuentas, en la prospección arqueológica persiste el problema de encontrar un equilibrio entre esfuerzo y rendimiento sin renunciar a una información de la máxima calidad posible. Al mismo tiempo continúa existiendo una gran diversidad de soluciones metodológicas en función del modelo de distribución del registro arqueológico que se maneja. En estas páginas lo que se plantea es la solución concreta adoptada para afrontar este tipo de cuestiones en el marco de un proyecto de investigación actualmente en curso.

\section{UN PROYECTO REGIONAL: LA EVOLUCIÓN HISTÓRICA DE LOS PAISAJES AGRARIOS EN LA COMARCA DE LA SERENA (PROVINCIA DE BADAJOZ)}

El año 2000 el Departamento de Prehistoria del Instituto de Historia del CSIC, en colaboración con la Universidad de Extremadura, puso en marcha un proyecto de investigación centrado en la evolución del paisaje en la comarca de la Serena (Badajoz) desde la Prehistoria hasta la Romanización (Fig. 1). A partir de 2002 retomó la labor el entonces recién creado Instituto de Arqueología de Mérida manteniendo su colaboración con las anteriores instituciones. Dicho proyecto arranca a su vez de una prolongada labor de excavación en

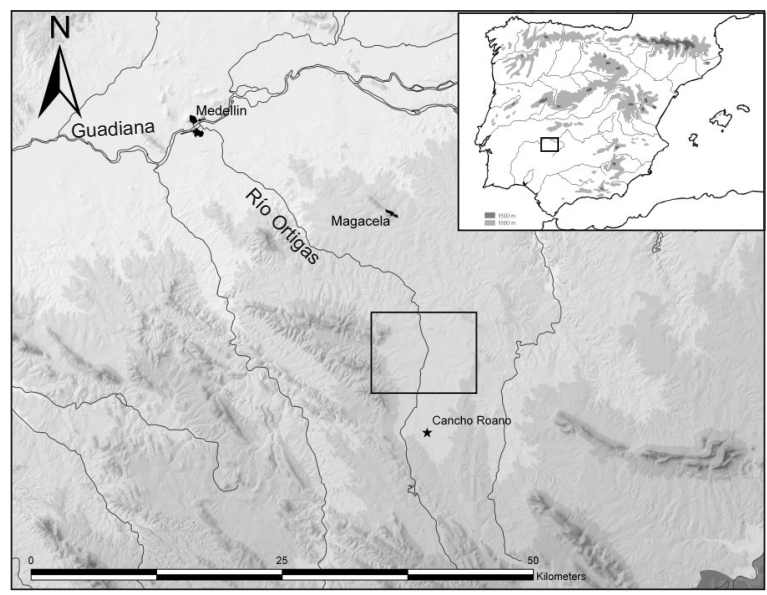

Fig. 1. Localización de la Comarca de La Serena en la Península Ibérica. El recuadro delimita la zona de prospección.
Cancho Roano (Maluquer de Motes 1981, 1983; Celestino Pérez 1996, 2003; Celestino Pérez y Jiménez Ávila 1993), y se planteó ante la necesidad de una visión espacial y cronológicamente más amplia para entender los procesos económicos y sociales que dan sentido y contexto a este enclave.

Este cambio de perspectiva se tradujo en la incorporación de la prospección de superficie como una de las herramientas clave en el proceso de investigación. Esto a su vez supuso enfrentarse al registro e interpretación de un complejo palimpsesto de materiales distribuidos a través del paisaje, resultante de un prolongado proceso de actividad en un paisaje intensamente humanizado. La estrategia específica adoptada fue diseñada por Antonio Gilman, quien planificó y codirigió las prospecciones del primer proyecto de investigación desarrollado en La Serena.

A grandes rasgos, el procedimiento de estos primeros trabajos se orientó tanto a la localización y delimitación de las principales concentraciones de material como entidades discretas, como al estudio de las distribuciones de menor densidad. Para ello se planteó un rastreo sistemático de las parcelas agrícolas con un reducido intervalo entre prospectores. Gracias a este modus operandi es posible obtener una imagen de alta resolución de la variación en densidad y características del material de superficie en el conjunto del área de prospección. Se asume que esta estrategia puede ser una vía de consecución de los siguientes objetivos:

- Determinar la extensión y forma de las distribuciones de material identificables mediante prospección.

- Determinar la secuencia ocupacional y la existencia o no de variaciones temporales en la localización de zonas de actividad.

- Obtener datos sobre la estructura y función de los asentamientos humanos.

- Valorar los factores que han afectado hasta el presente la conservación de los depósitos arqueológicos y cuantificar su incidencia a través del área estudiada.

- Estimar la influencia de estos y otros factores en la visibilidad del material arqueológico en el terreno. Ésta es una cuestión crucial para poder ponderar la representatividad del registro de superficie.

- Proporcionar información para la evaluación de riesgos potenciales de afección a los restos.

Durante los años 2000 a 2002 los esfuerzos se concentraron en el estudio intensivo del entorno 
del edificio protohistórico, estableciendo un radio de tres kilómetros alrededor del mismo. Como resultado se cuenta con un registro muy detallado de los indicios superficiales a lo largo del Arroyo Cagancha (junto al cual se localiza Cancho Roano), el tramo del río Ortigas entre Zalamea y la confluencia entre ambos cursos de agua. Los resultados de esta intervención han sido objeto de algunos análisis preliminares (Celestino Pérez y Walid, 2003; Nieto Masot et al. 2003). Actualmente está en marcha la revisión de las cerámicas recuperadas para obtener una adecuada valoración cronológica de las ocupaciones documentadas (2).

A partir del año 2004 la continuación de los trabajos de prospección tuvo como objetivo principal incrementar nuestro conocimiento sobre el valle del Ortigas, ya que este río se define como un claro eje articulador de la comarca, conectando las vegas altas del Guadiana con los corredores naturales de acceso hacia Córdoba y Ciudad Real.

Se trata además de un espacio jalonado por importantes enclaves de época protohistórica y romana, que jugaron un papel determinante en la ordenación política y la explotación económica del territorio. Aunque el estudio tiene un carácter diacrónico, nos interesaba en particular conocer las transformaciones que a escala del paisaje supusieron la crisis de las formaciones sociales prerromanas y la implantación romana.

\section{LOS OBJETIVOS DE LA CAMPAÑA DE 2007}

La disponibilidad de nuevos recursos materiales y humanos en el Instituto de Arqueología ha supuesto, desde 2006, un nuevo impulso a los trabajos de prospección en La Serena. Los objetivos concretos en esta etapa fueron dos. Por un lado, se planteó abordar la prospección sistemática del curso medio del Ortigas, siguiendo los criterios de delimitación que se describen más adelante. El carácter intensivo de la estrategia adoptada fue

(2) Los resultados de un análisis espacial de los indicios de superficie para valorar la evolución diacrónica del paisaje en torno a Cancho Roano fueron presentados en la comunicación de S. Celestino y V. Mayoral Herrera: "Intensive survey and protohistoric settlements in the middle Guadiana basin (Badajoz, Spain)" en el marco del congreso "Hidden Landscapes of Mediterranean Europe. Cultural and methodological biases in pre- and protohistoric landscape studies" celebrado en la Universidad de Siena los días 25-27 de mayo de 2007. La edición permanece en prensa. orientado no tanto a reconstruir la totalidad de la estructura del poblamiento, como a identificar pautas generales en la toma de decisiones sobre la ocupación del espacio. Por otro, se empleó una estrategia de trabajo más selectiva para obtener documentación sobre tipos de asentamiento característicos de la transición entre la protohistoria y la etapa romana en la comarca de La Serena. Se trata de los denominados recintos-torre. Estas construcciones fueron objeto de una amplia labor de investigación entre finales de los años ochenta y los noventa del siglo pasado (véase como referencias más recientes Ortiz Romero 1995; Rodríguez Díaz y Ortiz Romero 1998, 2003, 2004). No obstante, aún no disponemos de la publicación de un catálogo detallado, ni de las memorias de las intervenciones realizadas en varios de ellos. Nuestro propósito al respecto es obtener un registro de estos sitios lo más detallado posible, a fin de aportar nuevos datos así como plantear nuevos problemas en torno a su interpretación. Actualmente persiste una viva discusión acerca de este fenómeno centrada especialmente en la funcionalidad y sentido histórico de los recintos en su contexto territorial.

\section{LA DELIMITACIÓN DEL ÁREA DE TRABAJO}

Como hemos mencionado ya, el ámbito de trabajo elegido se define grosso modo a partir de los límites de la cuenca del río Ortigas en su curso

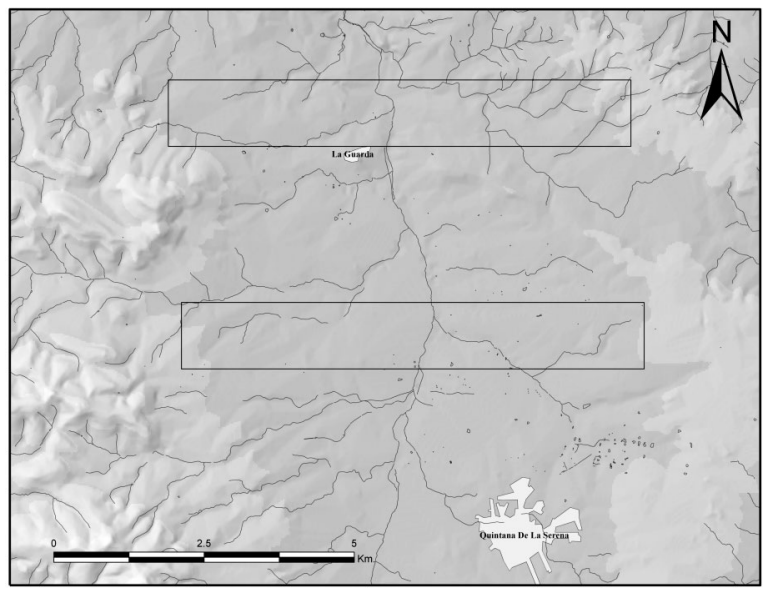

Fig. 2. Situación de los transectos para la prospección intensiva del curso medio del río Ortigas. 
medio. Se trata de una amplia depresión centrada en la actual población de Quintana, que se cierra hacia el Este por las elevaciones que definen el espacio interfluvial con la cuenca del Guadalefra. Hacia el Oeste la zona queda delimitada por las sierras cuarcíticas del Arrozao y la Agalla. Por el Norte el espacio de trabajo elegido encuentra su límite natural en el contacto entre las franjas de pizarras de la zona de La Guarda y el batolito de La Haba-Magacela. Este contraste geológico se refleja nítidamente en un cambio del paisaje. La topografía suave y alomada, deforestada casi por completo y cubierta por los cultivos de secano, da paso en la zona granítica al dominio total de una dehesa salpicada de afloramientos rocosos y dedicada enteramente a pastizal (Figs. 2 y 3 ).

Nuestra intención fue analizar el comportamiento de las distribuciones de superficie, en función de los diferentes tipos de terreno presentes en el área comprendida por estos límites. En este sentido las principales zonas homogéneas que se podrían diferenciar son las siguientes.

En primer lugar distinguimos la presencia de terrenos aluviales de la vega del Ortigas y sus arroyos tributarios: dado su escaso desarrollo no ocupan una porción significativa de terreno. Las reducidas zonas en que son explotadas están ocupadas por pequeñas explotaciones de huerta y viñedo.

En segundo lugar, terrenos se sustrato granítico. Ocupan la mayor parte de la zona de estudio. Forman relieves muy suaves, con algunos aflora-

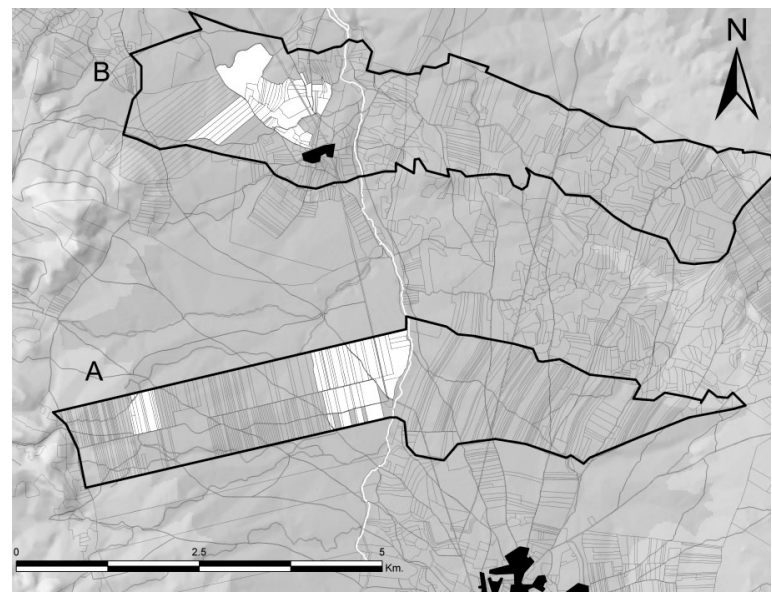

Fig. 3. Delimitación del área de prospección adaptándose al parcelario agrícola y localización de las zonas de trabajo. En blanco se indican las zonas ya prospectadas.

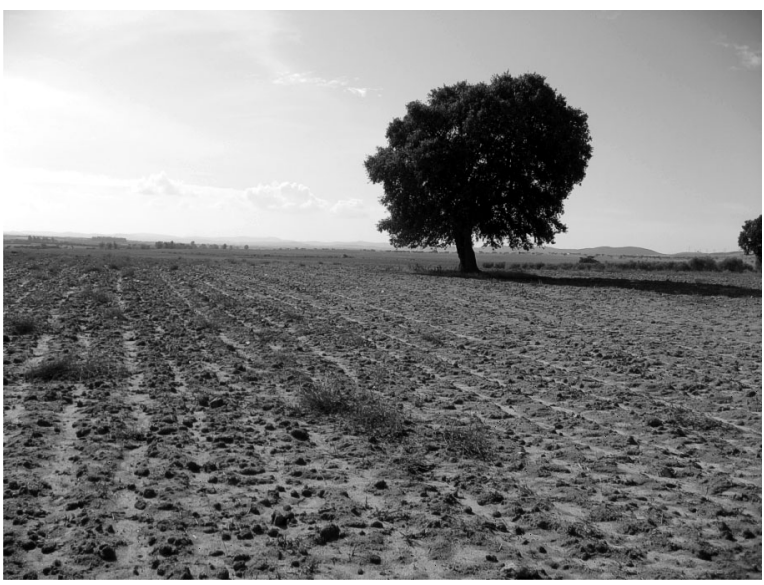

Lám. I. Vista de la zona de sustrato granítico en la que alterna la dehesa muy clareada con cultivos de secano (zona A).

mientos aislados entre suelos de textura arenosa. En algunos sectores están salpicados por superficies de glacis. Tradicionales espacios adehesados, su roturación desde el siglo XVIII ha dado lugar a un encinar muy abierto que coexiste con cultivos de secano (Lám. I).

Finalmente, puede diferenciarse una amplia franja de terrenos de sustrato pizarroso que corta transversalmente el valle del Ortigas en el Norte de la zona de prospección. Se trata de suelos más arcillosos y pedregosos, que sostienen un arbolado aún más escaso y están casi exclusivamente dedicados al cereal (Lám. II).

Estas dos últimas categorías fueron empleadas para definir dos grandes áreas de interés (que

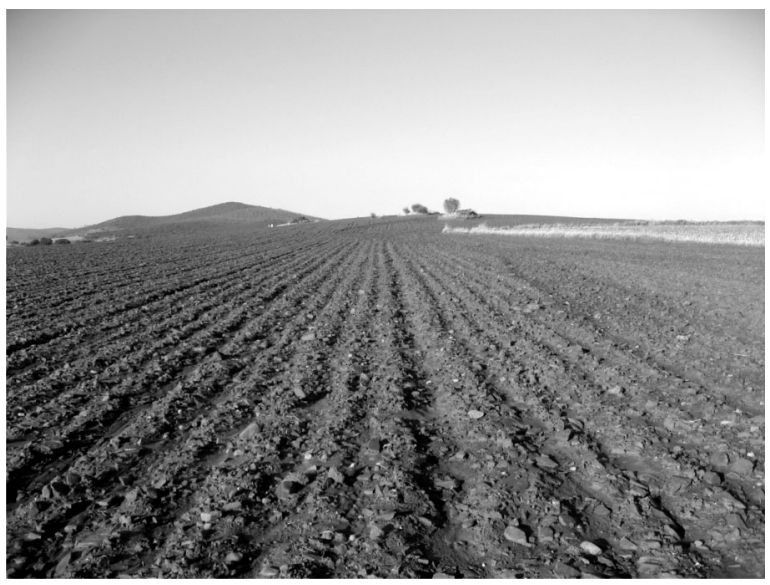

Lám. II. Vista de la zona B (suelos arcillosos con sustrato de pizarras).

T. P., 66, N. ${ }^{\circ}$ 1, enero-junio 2009, pp. 7-25, ISSN: 0082-5638 doi: $10.3989 /$ tp. 2009.09010 
convencionalmente denominaremos A y B). A fin de concretar algo más los objetivos se optó por seleccionar dentro de ellas conjuntos de parcelas agrícolas que nos permitieran trazar dos grandes transectos perpendiculares al cauce del río Ortigas. Para la zona A, la propia configuración del parcelario nos brindaba una oportunidad idónea, ya que existía una división muy regular que definía una franja de cinco kilómetros de longitud por un kilómetro de anchura que conectaba el curso fluvial con las sierras que delimitan el valle por el Oeste. La coherencia de este espacio era además reforzada por coincidir con una plataforma delimitada por dos arroyos que desaguan en el Ortigas. Respecto a la zona B aunque mucho menos homogénea, la división en parcelas pequeñas permitió igualmente definir una muestra del terreno transversal al río.

\section{DESCRIPCIÓN DEL MÉTODO}

La estrategia de prospección adoptada tuvo un carácter intensivo. Idealmente su resultado sería un registro exhaustivo tanto de la distribución del material, como de sus características y estado de conservación. Esto conduce a la necesidad de aplicar un sistema de muestreo estructurado en dos etapas sucesivas. En la primera se pretende realizar una estimación de la densidad global de materiales en superficie. El objetivo de esta labor es delimitar las áreas de mayor concentración de indicios, determinando su forma e importancia. Igualmente nos interesaba cartografiar las zonas con densidades más débiles así como las áreas completamente vacías de ítems en superficie. Una vez obtenida esta imagen global de las distribuciones, la segunda fase tiene como objetivo definir cualitativamente las dispersiones localizadas, realizando una recogida y descripción del material de forma pautada mediante una estrategia de muestreo. En todo el desarrollo del trabajo se contó con un equipo de prospectores que contaban con experiencia previa en prospecciones de superficie.

\subsection{Un primer paso: cuantificar y delimitar}

El reconocimiento sistemático de la zona de prospección fue estructurado en función de las parcelaciones agrícolas. A lo largo de todo el pro- ceso de trabajo se intentó aprovechar al máximo la adaptación a la morfología del terreno, tal y como se ha preconizado en otras experiencias recientes de prospección intensiva (como por ejemplo las desarrolladas en Segeda, Burillo et al. 2005) (Lám. III, A y B). Esto facilitó enormemente el desarrollo de la prospección. Cada parcela fue recorrida con un intervalo de 10 metros entre prospectores. Este nivel de intensidad se consideró aceptable para lograr un equilibrio entre esfuerzo invertido y cantidad de superficie cubierta por jornada, garantizando además un alto índice de probabilidades de detectar dispersiones de pequeño tamaño o indicios de menor entidad. Por otro lado, como se expondrá, el estudio intensivo de las áreas de interés localizadas se desarrolló en una segunda etapa del trabajo.

La equidistancia en el trazado de estos recorridos se consiguió amoldándose a la pauta que ofrecía el terreno mediante los surcos dejados por los arados y las alineaciones de cepas, olivares y otros cultivos. En la gran mayoría de los casos dichas referencias garantizaron una cobertura completa y regular de las parcelas. Este procedimiento se consideró una alternativa eficaz al trazado artificial de un sistema de referencia, bien con apoyo de señales visibles en superficie situadas con ayuda de aparatos topográficos, bien recurriendo a mallas o líneas virtuales proporcionadas por un receptor GPS. La primera opción presentaba el inconveniente de consumir una gran cantidad de tiempo en proporción a la mejora respecto a la utilización de los surcos. La segunda habría requerido disponer de varios equipos GPS de alta precisión, algo hoy por hoy poco operativo dado su elevado coste.

Para iniciar la inspección de cada parcela se trazaba un eje paralelo al lado mayor de la misma, señalizando en el suelo el inicio de cada trayecto. Cada prospector va equipado con un receptor GPS, tomando una posición cada vez que localiza en superficie cualquier tipo de ítem a lo largo de su recorrido, pero sin recoger nada. El resultado (Fig. 4) es una distribución de puntos que refleja la presencia global de materiales de todo tipo en superficie.

Un recurso ampliamente utilizado en algunos proyectos para estos recuentos de cantidades totales es el uso de "clickers" o contadores, con los que se registra el número de fragmentos en una determinada área (Mattingly 2000: 8). Para la representación espacial de esta toma de datos sue- 


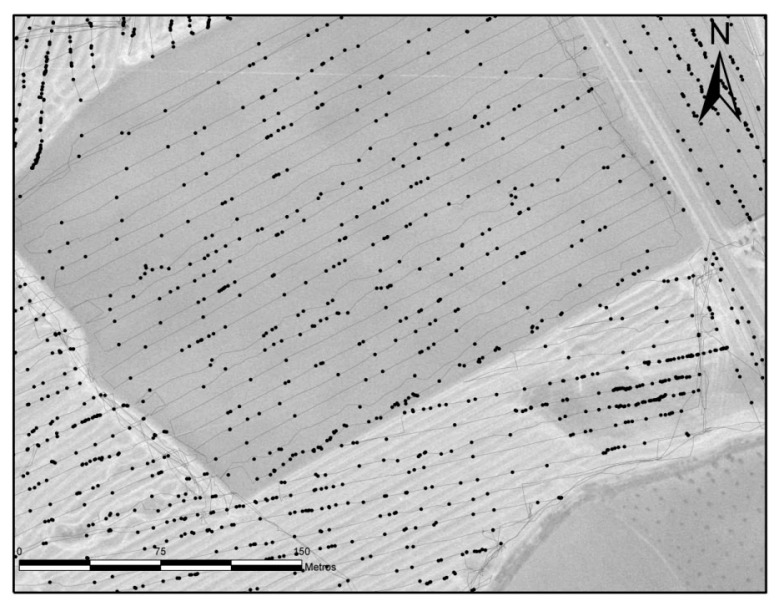

Fig. 4. Trazado de los recorridos de los prospectores (tracks de los GPS empleados) y dispersión de hallazgos a lo largo de los mismos. len utilizarse los polígonos de las parcelas, o bien establecerse mallas regulares (por ejemplo, cada cinco metros, como es el caso de los trabajos desarrollados en Beocia, ver Bintliff y Snodgrass 1985). Habitualmente en este tipo de trabajos se consume mucho tiempo en el planteamiento sobre el terreno de la rejilla de referencia para situar las observaciones. Por tanto, la toma directa de puntos puede agilizar bastante la obtención de este tipo de datos. Pese al gran volumen de información que esto supone, los ficheros generados resultan manejables.

Un inconveniente obvio de este sistema de registro es que no puede diferenciar ni tipos de materiales ni su cronología, ofreciendo únicamente el volumen total de ítems en forma de distribuciones "mudas". En nuestro caso se adoptaron algunas medidas para que esta información orientase la siguiente fase de trabajo. Todos los materiales
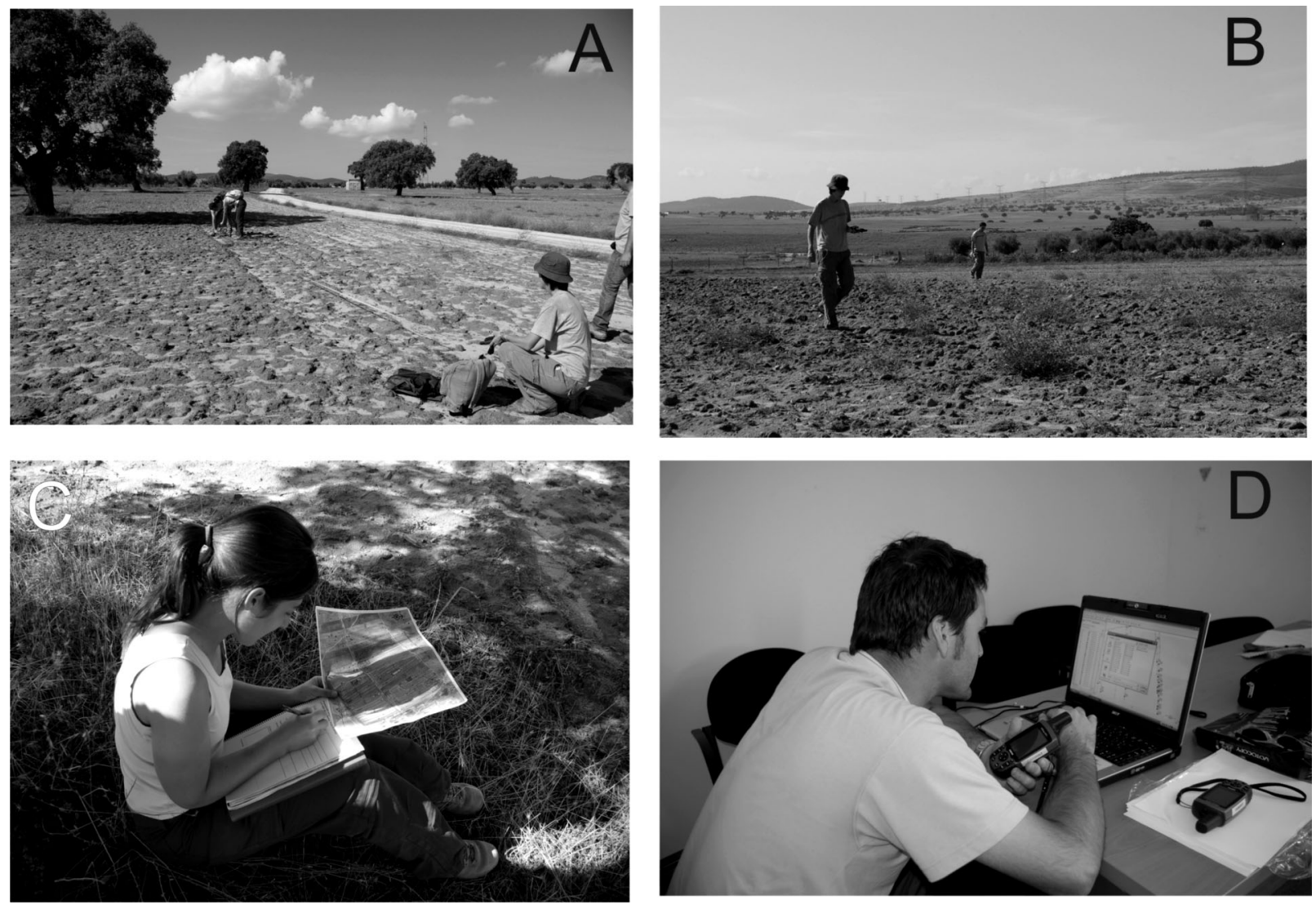

Lám. III. Desarrollo de la primera etapa de la prospección. A. Planteamiento del eje para los recorridos; B. Inspección de las parcelas; C. Cumplimentando la ficha descriptiva de una parcela; D. Descarga de los recuentos de fragmentos en un entorno SIG. 
de superficie que de manera inequívoca fuesen recientes (vidrios, lozas, ladrillo...) fueron identificados con un código diferente al resto. Esto permitió delimitar las zonas más "contaminadas" con vertidos modernos. Por otro lado también se introdujo un código específico siempre que se reconocía en zonas de baja densidad un elemento claramente antiguo (por ejemplo, la pestaña de una tegula). En el caso de que se tratara de cerámicas con un valor diagnóstico se recogían e identificaban con una sigla correspondiente al GPS empleado, la fecha y el número del punto. Si se estaba trabajando en zonas de densidad elevada y con abundante material claramente antiguo se reservaba la toma de este tipo de datos para la segunda fase del trabajo.

\subsection{Precisión, esfuerzo y rendimiento}

El modelo de GPS utilizado en la primera etapa del trabajo se encuentra dentro de la gama de
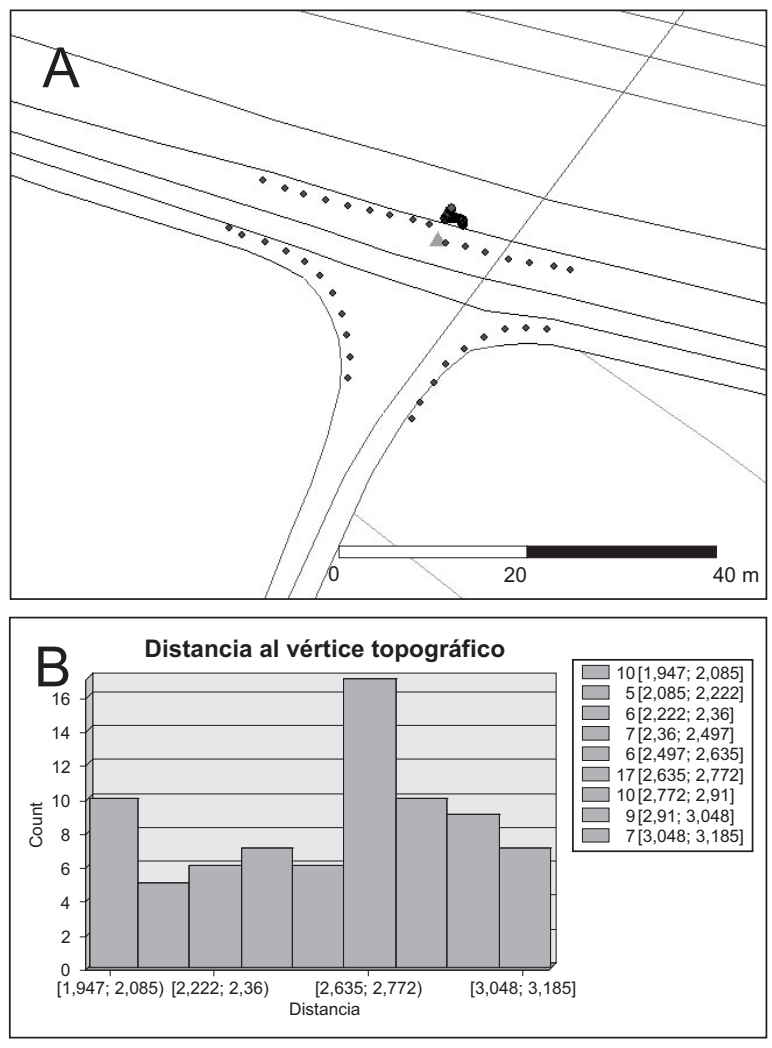

Fig. 5. Estimación del error de los receptores GPS empleados en la primera fase de la prospección. A. Mediciones realizadas sobre un vértice topográfico y un camino reflejados en un mapa a escala 1:10000; B. Gráfico con la distancia al vértice de los puntos tomados sobre el mismo. altas prestaciones dentro de los aparatos de uso no-profesional. A día de hoy, el principal inconveniente que presenta este tipo de aparatos es la limitada precisión de las mediciones que se pueden obtener. Se trata de receptores que captan una única frecuencia y carecen de sistemas para discriminar y garantizar la calidad de la señal. Tampoco permiten el proceso posterior de los datos.

Por todo ello el error típico que introducen puede estar entre dos y tres metros (Fig. 5). No obstante hay que señalar que la calidad de la señal mejora en parte gracias a la habilitación del sistema EGNOS de que disponen estos aparatos, aportando corrección diferencial en tiempo real. Por otro lado, aunque existe la imprecisión mencionada en coordenadas absolutas, la posición relativa de los puntos obtenidos presentaba un error siempre inferior al metro.

Frente a los inconvenientes señalados hay que destacar las ventajas de este método. En primer lugar, el coste reducido de los receptores hace viable el equipar con uno de ellos a cada prospector. En segundo lugar hay que resaltar la agilidad y rapidez con la que se puede generar una cartografía global de la densidad de materiales en zonas muy extensas. Pensamos, en fin, que es despreciable el error introducido considerando la intervención de diversos factores, como el desplazamiento del material por efecto de la erosión o el arado, y teniendo en cuenta el tamaño medio de las dispersiones. Lo realmente significativo en esta etapa del trabajo fue captar una imagen de conjunto mediante un reconocimiento inicial del terreno que no encareciese demasiado el coste en tiempo y esfuerzo de la prospección.

Una vez inspeccionada cada parcela, se cumplimentaba una ficha de campo en la que se incluía toda la información relevante sobre los elementos arqueológicos detectados en ella (Lám. III, C). Igualmente se señalaba cualquier alteración reciente que pudiera amenazar su conservación (canteras de granito, abundantes en la zona, nuevas construcciones...). Respecto a las condiciones del reconocimiento del terreno, se registraron mediante descripciones genéricas datos sobre la visibilidad, la topografía, el tipo de sustrato, el tipo de suelo (color, textura, compactación...) o el uso actual. Se tuvieron en cuenta condiciones muy específicas que en la práctica tienen mucha influencia en la visibilidad (por ejemplo si un terreno en barbecho había sido arado recientemente o si estaba lavado y compactado por la llu- 
via). Se consideró poco operativo el empleo de valores preestablecidos para rellenar las fichas o el empleo de escalas numéricas (por ejemplo para la visibilidad). Las apreciaciones visuales de los prospectores fueron anotadas y además esbozadas sobre una copia en papel de la ortofotografía de la zona (3).

El registro obtenido con los GPS era regularmente volcado en un portátil a medida que se desarrollaba la prospección (Lám. III, D). El software empleado para gestionar estos datos fue ArcGIS. Gracias a una extensión añadida al escritorio de trabajo fue posible generar directamente una capa vectorial sin necesidad de conversiones de formato o ajustes de la proyección cartográfica.

Estas distribuciones de puntos fueron utilizadas como base para generar mapas de densidad de material mediante técnicas de interpolación. Aunque se crearon resultados para el conjunto del área prospectada, habría que considerar el sesgo introducido por las condiciones particulares de cada parcela, estimándose una medida prudente comparar los resultados con mapas de densidad parciales. Los métodos disponibles para realizar estas estimaciones son muy variados y requieren la toma de decisiones que influyen notablemente en el resultado Por nuestra parte optamos por el método kernel. Con este nombre se designa a la función matemática que describe la forma del "abultamiento" producido por cada punto (Wheatley y Gillings 2002: 186). Frente a la estimación simple de la densidad, este procedimiento permite generar superficies suavizadas y visualmente más comprensibles. Uno de los parámetros que es posible modificar con este sistema es la amplitud del abultamiento, que se calcula en función de la anchura de banda. Ésta se establece como la distancia en torno a cada punto empleada para buscar otros puntos adyacentes y que quedan así englobados en una agrupación. Como señalan Baxter et al. (1997: 348) estos intervalos son análogos a los de un histograma. Un radio de distancia reducido genera un mapa de densidad que refleja las pequeñas variaciones locales, mientras que un valor elevado tendría en cuenta los puntos más alejados y produciría una imagen mucho más suavizada. Podemos así obtener varios resultados

(3) Disponemos para el trabajo de la ortofoto elaborada por la Dirección General de Ordenación del Territorio de la Junta de Extremadura. Las imágenes manejadas corresponden al año 2002 y tienen una resolución espacial de $50 \mathrm{~cm} /$ píxel. para explorar la distribución de ítems creando imágenes más sintéticas y globales o más detalladas (Fig. 6).

\subsection{Segundo paso: definiendo la naturaleza de las dispersiones}

Uno de los problemas que se ha planteado de manera más frecuente en prospección es determinar la forma y la extensión de las dispersiones de material. La delimitación de las mismas como entidades discretas de un modo directo sobre el terreno exige establecer el umbral a partir del cual la densidad de hallazgos decrece significativamente. En algunos casos esto se logra trazando radios tomando como centro la zona con mayor presencia de materiales (véase por ejemplo Bintliff y Snodgrass 1985: 130-131). Estas demarcaciones pueden resultar arbitrarias, especialmente si se trabaja en zonas con un elevado "ruido de fondo", lo que exige a fin de cuentas una valoración de la importancia de este último. La alternativa (que es el fundamento del procedimiento que hemos empleado) consistiría en registrar la variación de la densidad a través del espacio para decidir a posteriori dónde establecer los límites. Esto se determinó sintetizando los valores obtenidos mediante la reclasificación en categorías discretas. Por tanto, las dispersiones son identificadas por su "contraste" con el ruido de fondo, actualmente estamos trabajando en un módulo que trata de automatizar la elección de umbral para identificar concentraciones de material, que se basa en esencia en la reclasficación en categorías de la densidad de material. Los resultados preliminares han resultados satisfactorios, aunque será necesario probarlo ante distintas circunstancias. De esta manera el ámbito de la prospección quedó subdividido en espacios de alta, media y baja presencia de materiales. Los intervalos se definieron en función del rango de valores presente en cada zona. Las áreas así diferenciadas se convirtieron en la base para estructurar la siguiente etapa del trabajo que, como ya dijimos, consistió en la realización de muestreos. Se esperaba obtener con ellos una imagen representativa de las dispersiones en cuanto al tipo de material, su fragmentación, rodamiento, forma, posible cronología, etc. De nuevo se priorizó el desarrollo de una estrategia que permitiera alcanzar los objetivos propuestos con una relación aceptable entre inversión de esfuerzo y resultados. 

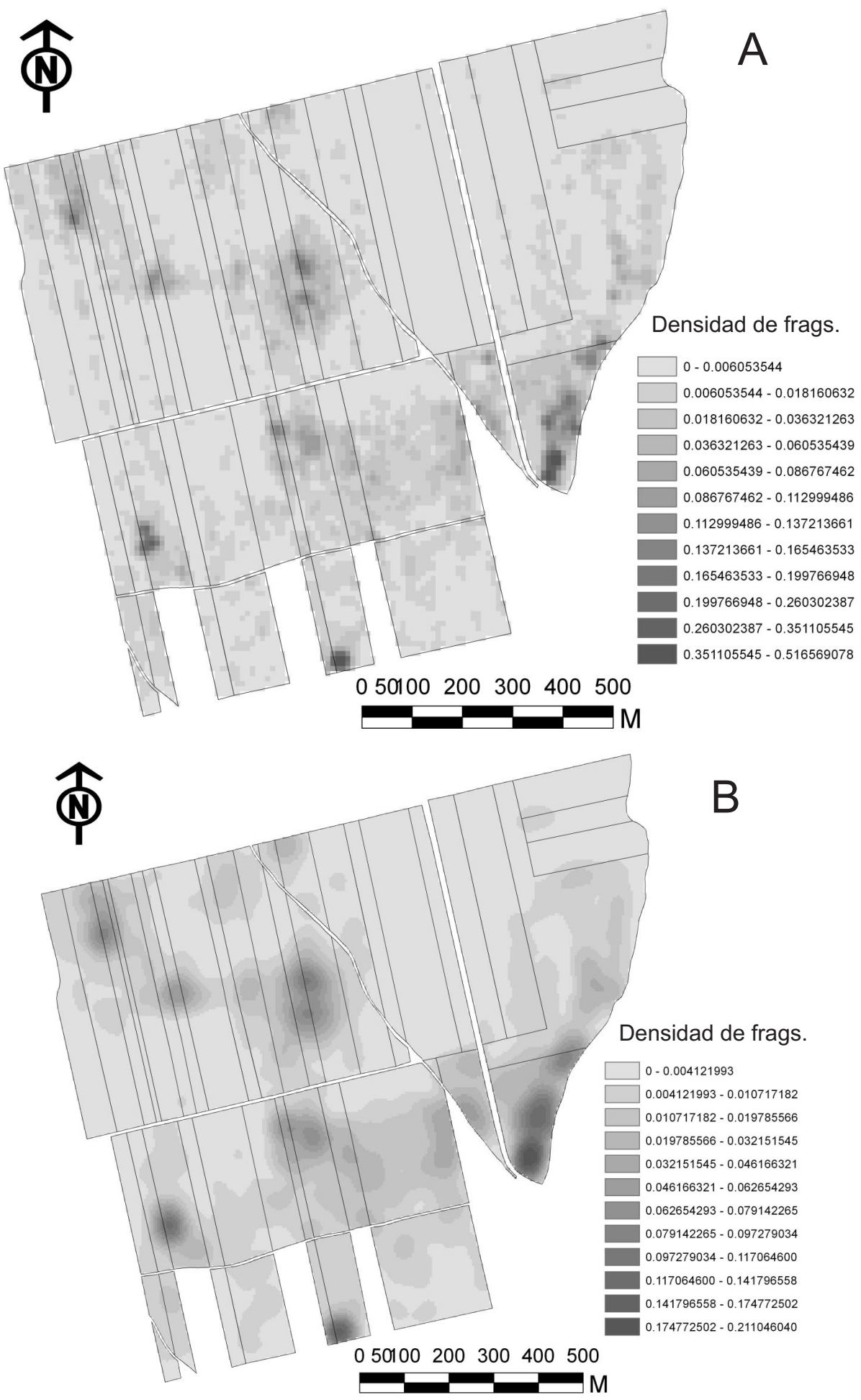

Fig. 6. Generación de mapas de densidad de hallazgos en la zona a con un radio de 20 (A) y 50 (B) metros de búsqueda empleados para el cálculo.

T. P., 66, N. ${ }^{\circ} 1$, enero-junio 2009, pp. 7-25, ISSN: 0082-5638 doi: $10.3989 /$ tp. 2009.09010 


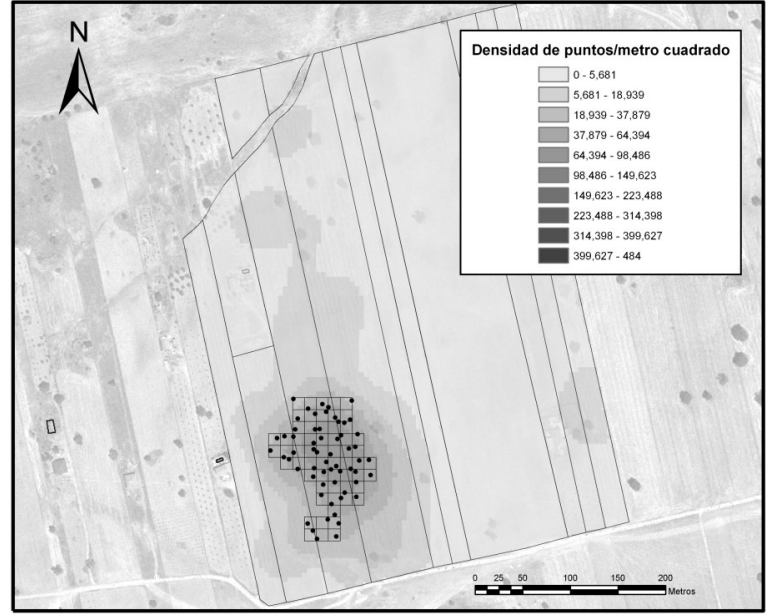

Fig. 7. Planteamiento de una malla de muestreo sobre una zona de alta concentración de hallazgos definida en la primera fase de la prospección.

Optamos por un muestreo aleatorio sistemático no alineado, que garantizase la igualdad de probabilidades de cada punto para ser seleccionado, pero evitando la formación de espacios vacíos de observaciones (Banning 2002: 117). Este tipo de muestreos ha resultado eficiente en numerosas prospecciones a escala de sitio (véanse como ejemplos en el ámbito peninsular: Gutiérrez et al. 1998; Keay et al. 1991; Chapa Brunet et al. 2004). Para cada dispersión de material trazamos una malla regular de cuadros de $12,5 \times 12,5 \mathrm{~m}$. Dentro de cada uno de ellos fue seleccionado aleatoriamente un punto de muestreo. Adaptamos siempre la malla a cada dispersión de material, procurando que éstas abarcaran la zona "difusa" de menor densidad de material que suele delimitarlas (Fig. 7). Cada punto era documentado mediante una unidad de muestreo consistente en un marco de un metro cuadrado. Así se lograba cubrir de una manera homogénea aproximadamente un $2 \%$ de la superficie de cada dispersión. La elección de este procedimiento se basa en la asunción de que en la representatividad del muestreo para conocer la población de origen, influirá más el número total de observaciones que la superficie prospectada en términos absolutos.

Las distribuciones de puntos para la toma de muestras se generaron en el entorno de ArcGIS y se cargaron directamente en un GPS para facilitar su localización y documentación sobre el terreno. Esta vez se empleó un receptor capaz de aportar una precisión submétrica en tiempo real (4) (Lám. IV). Este tipo de dispositivos incorporan una PDA en la que es posible instalar aplicaciones de SIG móvil como Arcpad, para trabajar con diferentes diseños de muestreo (véase por ejemplo las "mallas virtuales" de prospección empleadas por Campana (2006) en trabajos desarrollados por la Universidad de Siena).

La mayor parte del material localizado en el interior del cuadro era recogido para su posterior estudio. Únicamente se describió y desechó en campo el material de gran volumen o nulo valor diagnóstico (aunque albergamos serias dudas sobre la posibilidad de establecer criterios fiables respecto a esto último). En todos los casos se registró el tipo de ítem, su peso y su rodamiento. Para el registro estandarizado de este último se recurrió a una sencilla escala con valores de 1 (muy poco o nada rodado) a 3 (muy rodado). Aunque este sistema introduce indudablemente un componente de subjetividad, la experiencia en trabajos anteriores ha mostrado que puede ser un indicador expresivo para establecer diferencias (Mayoral Herrera et al. 2006: 99-100). Los fragmentos cerámicos también fueron clasificados en función del tipo de producción de acuerdo con una serie de categorías previamente definidas:

- Cerámica a mano

- Cerámica a torno de cocina (pastas poco depuradas, cocciones reductoras o alternantes, desgrasantes gruesos, tratamientos superficiales tos$\cos . .$.

- Cerámica a torno común (pastas más depuradas, cocción generalmente oxidante, desgrasantes finos, engobes o alisados de mayor calidad...)

- Categorías más específicas, generalmente minoritarias como las cerámicas barnizadas, vidriadas, etc.

- Material constructivo (teja árabe, tegula, ladrillo, etc.).

La combinación del conteo de piezas con el peso y el rodamiento se consideró útil para definir la naturaleza de las dispersiones, diferenciando conjuntos muy afectados por alteraciones posdeposicionales o identificando pautas de desechado no asociadas a asentamientos. El cruce de esta información con una cartografía detallada

(4) Se empleó un colector de mano monofrecuencia de Trimble, modelo Geoexplorer XT. Su capacidad para recibir correcciones en tiempo real del sistema EGNOS, junto con el procesado posterior de los datos aseguraron una precisión submétrica durante la mayor parte del trabajo. 


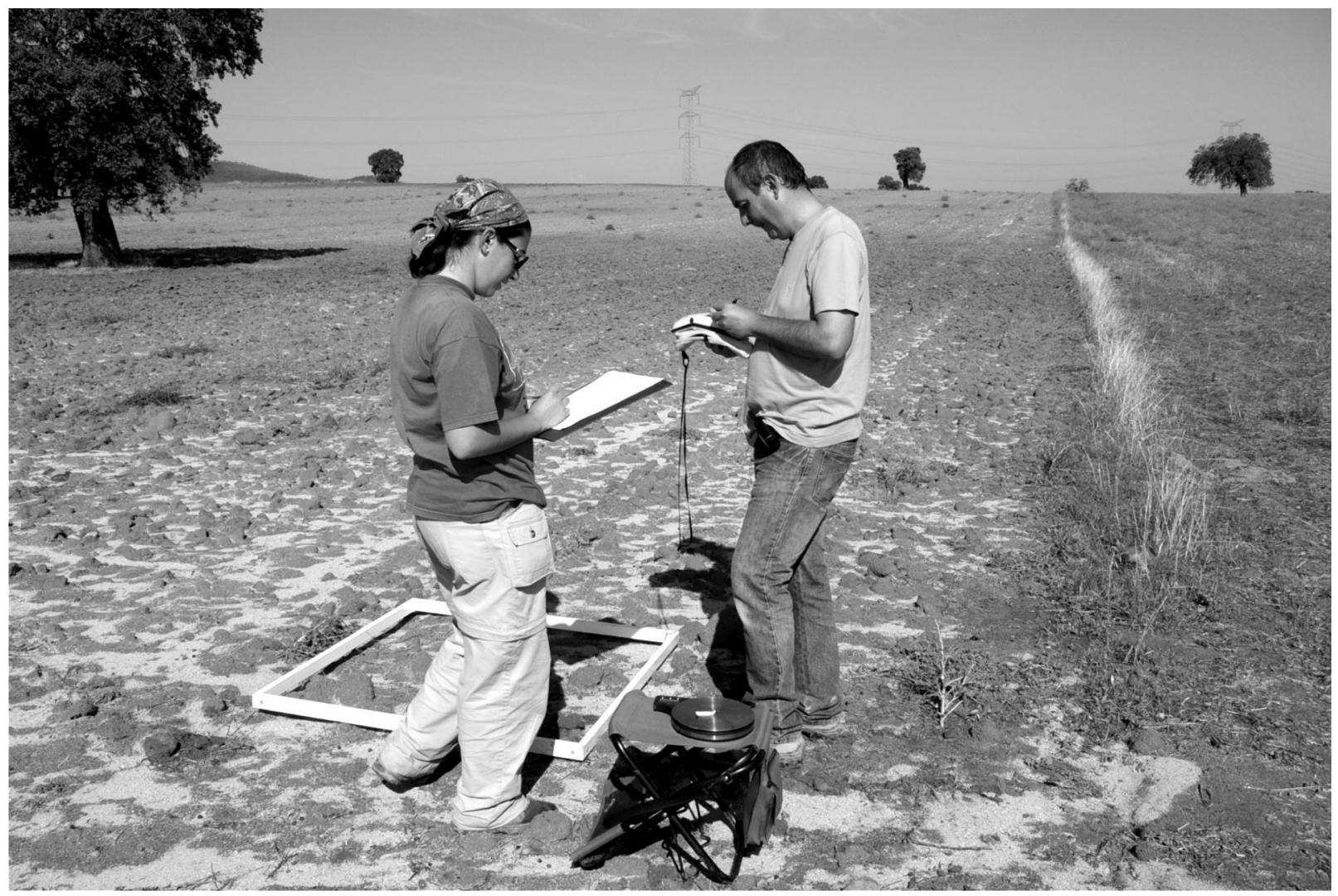

Lám. IV. Desarrollo del muestreo sistemático de una dispersión.

sobre la topografía y el tipo de terreno (sustrato geológico, suelos, uso actual...) podrá ayudarnos a entender el proceso de formación y alteración de los conjuntos de superficie.

El efecto de las decisiones tomadas sobre el número y distribución de las unidades de muestreo plantea algunas dudas y dificultades. Nuestra elección a priori fue mantener el tamaño de la cuadrícula y el número de unidades de muestreo en la totalidad de las dispersiones, a fin de efectuar comparaciones directas entre ellas. Sin embargo, las diferencias en cuanto a densidad y homogeneidad de los materiales que las componen hacen necesario un ajuste que garantice la representatividad de los datos para caracterizar la naturaleza de una dispersión. Otro problema planteado fue la capacidad de los muestreos para detectar los elementos de distribución más minoritaria e irregular. Éste sería el caso de la identificación de ocupaciones prehistóricas en el interior de conjuntos con múltiples períodos representados. En general, los sitios prehistóricos se caracterizan con mayor frecuencia por la atonía de su registro, y puede resultar más complejo hallar evidencias diagnósticas. Del mismo modo, numerosas producciones comunes de vajilla de mesa y almacenaje realizadas con técnicas de tradición local podrían estar indicando la presencia de una ocupación republicana o anterior. Sin embargo, en ausencia de materiales con alto valor diagnóstico como las importaciones itálicas, estos importantes matices cronológicos son difíciles de captar.

\section{RESULTADOS Y DISCUSIÓN}

El procedimiento descrito permitió un reconocimiento intensivo de una superficie de 250 ha en un total de 10 días de trabajo de campo. En la campaña del año siguiente, elevando a siete el número de prospectores equipados con GPS fue posible prospectar más de 900 ha en el mismo lapso de tiempo. Esto ha permitido completar el transecto de la zona A.

Junto con el recuento global de ítems a lo largo de los transectos se completó un muestreo de 


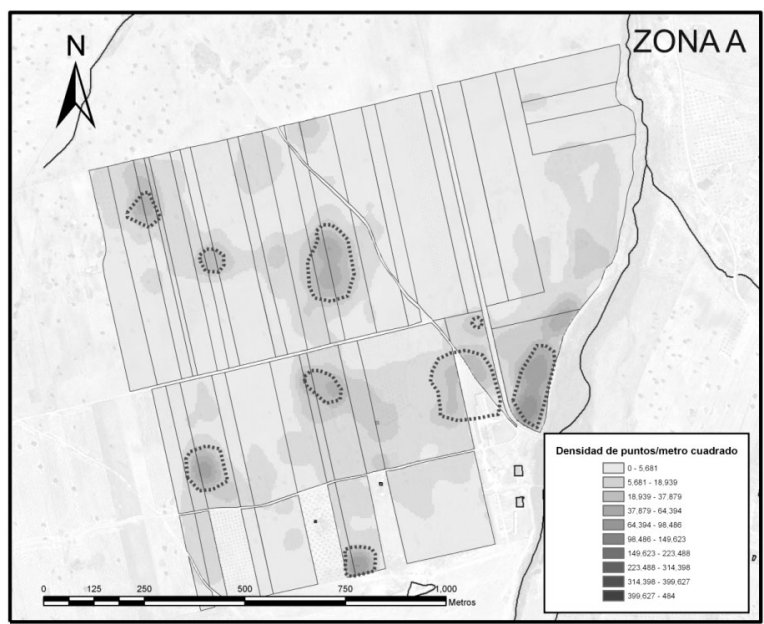

Fig. 8. Densidad global de fragmentos en la zona A a partir de los recuentos de la primera fase de prospección. En línea discontinua se delimitan las áreas seleccionadas para el muestreo.

la mayoría de las concentraciones detectadas (que fueron un total de 15). Tanto la primera como la segunda fase del trabajo fueron ejecutadas por sendos equipos de tres prospectores. Respecto a los resultados, hay que destacar en primer lugar las diferencias entre las dos zonas de prospección definidas.

En la denominada zona A se constató una gran abundancia de concentraciones de material, que contrastaban con bastante claridad respecto al ruido de fondo (Fig. 8). Este último estaba mayoritariamente compuesto por material latericio de cronología reciente (tejas, ladrillos...) aunque como comentaremos en algunos casos se trataba de cerámicas a torno oxidantes muy rodadas que de un modo preliminar podrían asignarse a época romana o anterior. La densidad media de ítems derivada de los datos de los transectos fue muy similar a la de la zona B (0,01 fragmentos/metro frente a 0,013$)$. En cuanto a las dispersiones delimitadas identificables como "sitios" fueron en total 11, dentro de una superficie de 150 ha. Esto supone una destacada concentración, que puede explicarse por la cercanía del cauce del Ortigas. Aún no tenemos los resultados para el conjunto del transecto a lo largo del valle, por lo que no podemos contrastar esta posibilidad. Las ocupaciones documentadas van desde el Neolítico hasta época moderna. De un modo preliminar puede señalarse la presencia de al menos tres dispersiones de material romano, un posible caso de pequeño enclave del Bronce Final y un depósito claramente asignable a la Primera Edad del Hierro. No se detectaron indicios claros de ocupación para la Segunda Edad del Hierro ni para la etapa de romanización, aunque queda pendiente el estudio detallado de las cerámicas.

Frente a la relativa facilidad con que se podía individualizar concentraciones de material en la zona $\mathrm{A}$, en la $\mathrm{B}$ el rasgo más destacado fue la presencia de un denso manto de material, mayoritariamente compuesto por tejas y cerámicas toscas, correspondiente al "halo" de la pequeña aldea de La Guarda, un núcleo de origen medieval situado a escasos $300 \mathrm{~m}$ al Sur del área prospectada (Fig. 9). La densidad de fragmentos tan elevada en algunas parcelas planteaba un serio problema para la identificación de dispersiones más reducidas y ocultaba elementos más antiguos del material de superficie. Sólo en dos casos fue posible diferenciar conjuntos que por el rodamiento y características del material se consideraron indicios de ocupación antigua.

Si descendemos al comentario de resultados más concretos, podemos ver cómo la estrategia adoptada nos muestra la complejidad de las distribuciones de superficie. Este hecho en sí mismo no adquirirá su verdadera trascendencia hasta que no dispongamos de áreas prospectadas de una extensión significativa. No obstante, podemos señalar algunas observaciones.

En primer lugar, resultó relativamente sencillo definir la forma y tamaño de los asentamientos de mayor entidad, clasificables como explotaciones rurales, principalmente de época romana (a falta de un estudio del material no podemos ofrecer una clasificación cronológica más detallada). Sin embargo, la toma de muestras puso en evidencia el problema de la visibilidad dentro de estos conjuntos de fases de ocupación peor representadas (por ejemplo, cerámicas a mano que aparecen integradas en las dispersiones de sitios romanos).

En segundo lugar, en repetidos casos fue posible delimitar pequeñas dispersiones que en ocasiones corresponden claramente a sitios de muy escasa entidad. Así parece ser en el caso de la que abarcaba poco más de $2.000 \mathrm{~m}^{2}$ sobre una suave loma. Se recuperó abundante material constructivo, entre el que cabe destacar un conjunto de tapaderas recortadas de pizarra. La cerámica a mano, sobre todo grandes contenedores de almacenaje, parece indicar una ocupación protohistórica. 


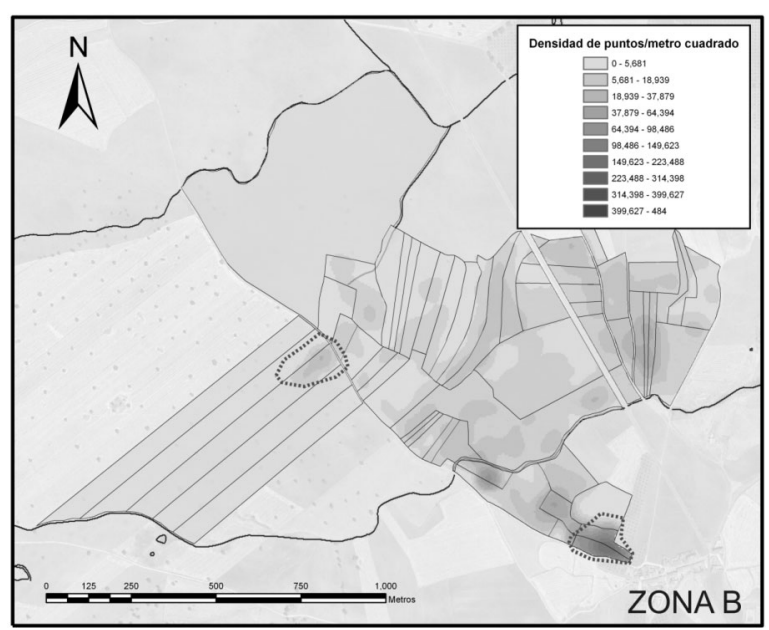

Fig. 9. Densidad global de fragmentos en la zona B a partir de los recuentos de la primera fase de prospección. En línea discontinua se delimitan las áreas seleccionadas para el muestreo.

Por otro lado, la intensidad en cuanto al intervalo entre prospectores permite tener confianza en cuanto a la probabilidad de detectar dispersiones de tamaño muy reducido. Es el caso de un conjunto de cerámicas localizado entre unos afloramientos rocosos que se extendía en un radio inferior a diez metros. Muy probablemente corresponden a depósitos aislados. El material a mano de cocción reductora y acabados bruñidos incluía algunos elementos de valor diagnóstico que permiten fechar el hallazgo en el Bronce Final.

Por último, hay que señalar cómo el muestreo de algunas dispersiones permitió establecer diferencias en varios niveles de intensidad en el ruido de fondo. Esto sucedió al analizar en detalle una de las "concentraciones" inicialmente definida como un sitio. Las formas y los tipos de producción cerámica indicaban una ocupación antigua, pero el fuerte rodamiento y la fragmentación del material marcaban una diferencia clara respecto a los demás conjuntos del entorno. Esto plantea la posibilidad de delimitar áreas de cultivo intensivo con restos de abonado relacionadas con asentamientos cercanos.

\section{PROBLEMAS Y APORTACIONES DEL USO DE MUESTREOS}

Con el muestreo probabilístico hemos querido, para empezar, desterrar procedimientos selec- tivos y poco sistemáticos en la recogida de materiales de superficie, que conducen a notables sesgos en la información. Pretendemos que las colecciones cerámicas sean muestras representativas de la composición de las dispersiones. Precisamente a partir de esta premisa esperamos que los muestreos permitan explorar en detalle las distribuciones, a fin de poder contrastar la existencia de variaciones cronológicas y funcionales. En cuanto a su análisis interno, los resultados fueron lógicamente desiguales en función de su complejidad. Aquellas que se correspondieron con una única ocupación, una superficie reducida y materiales muy homogéneos aportaron poca información más allá de una distribución de pesos, cantidad de fragmentos y rodamiento. En cambio en las dispersiones de mayor entidad y variedad cronológica la distribución de los materiales permitió establecer claras diferencias. El cruce de las estimaciones para cada tipo de ítem permite explorar la existencia de correlaciones significativas.

Siguiendo esa dirección, hemos tratado de comprender y explicar las dispersiones empleando "superficies" o modelos generados por procedimientos matemáticos que interpolen los valores obtenidos en los muestreos. Así creamos una capa raster donde cada una de las celdas representa el valor esperado para cada variable. Se produce de este modo una estimación muy visual sobre la distribución espacial y comportamiento de una variable (número de fragmentos de cerámica, peso de un determinado tipo de material, etc.) que únicamente se ha registrado a partir de observaciones en coordenadas concretas. Empleamos distintos procedimientos para interpolar nuestros datos, $y$, aunque no descartamos ensayar con otros en un futuro, hemos seleccionado aquel que, dada la naturaleza del muestreo, ofrece una mayor eficiencia y capacidad de análisis. El método elegido es la interpolación mediante splines bicúbicas. Con este tipo de cálculo podemos modelar cualquier fenómeno que presente una variación espacial (por ejemplo las cotas de un levantamiento topográfico). La interpolación entre las observaciones se realiza generando curvas cuyos tramos son generados de forma independiente mediante una función, en este caso polinomios bicúbicos. El ajuste de las curvas que producirá una superficie raster continua se supervisa mediante el ajuste de los cuadrados mínimos, un procedimiento que minimiza el riesgo de valores no deseados a lo largo de la curva. No pretende- 
mos analizar de forma excesivamente detallada las facilidades que ofrece este tipo de método matemático frente a otros, pero sí señalar que, en nuestro caso, sus ventajas principales son varias. En primer lugar, nos proporciona una estimación del error de interpolación, facilitando la cuantificación del ajuste entre los valores conocidos y la superficie generada. En segundo lugar, este procedimiento de interpolación mediante splines permite generar un modelo más ajustado a la superficie del área de trabajo, y una representación más realista del comportamiento espacial de las variables (Wheatley y Gillings 2002: 193). Por último, la resolución de la superficie raster no incide directamente sobre la interpolación, sino que depende directamente de la extensión de la superficie a estimar.

En el caso que presentamos como ejemplo, hemos utilizado el peso de cada tipo de material en cada unidad de muestreo para estimar la frecuencia con la que puede registrarse un determinado tipo de material en cada punto del área prospectada. Hemos escogido únicamente categorías que poseyeran suficiente entidad en términos estadísticos (material constructivo romano, teja moderna y cerámicas a torno), dado que no es factible utilizar estos procedimientos para analizar el comportamiento de elementos cuya presencia sea poco significativa. El resultado obtenido (Fig. 10) es un modelo en el que se registra el peso esperado para varios tipos de material en el conjunto de la superficie muestreada. El objetivo de generar estas imágenes parciales fue comparar la distribución de las diferentes categorías de ítems en busca de pautas identificables en su variación conjunta. Para poder evaluar de una forma más objetiva la posible existencia de asociaciones, recurrimos a una matriz de correlación obtenida mediante el coeficiente de correlación de Pearson. Comparamos los valores de cada una de las celdas de las superficies y establecimos estadísticamente si existían relaciones entre los tipos de material de una determinada dispersión (Tab. 1). Como es sabido, en una matriz de este tipo la correlación más consistente se produce cuando los valores positivos tienden a uno. La relación entre los materiales es más débil a medida que el índice de correlación se aproxima a cero, mientras que un valor negativo elevado indica una correlación inversa. Como puede verse, la distribución de fragmentos a torno es la más homogénea y no guarda una particular correlación con los otros materiales considerados. Tan sólo la comparación entre la teja moderna y la romana (y aún de un modo discreto) sugiere una pauta netamente diferenciada. Mas allá de la posibilidad que ofrece este proceder para establecer la existencia de patrones distintos, lo que se hace posible es evaluar y comparar la intensidad de las diferencias.

Por otra parte, hemos aplicado otros métodos para analizar los resultados de los muestreos, con resultados desiguales. Uno de ellos es el kriging. Los resultados de su aplicación no han sido completamente satisfactorios, aunque es un sistema que tiene en cuenta la creación de superficies de tendencias y expresa el error cuadrático medio que se genera. Por otro lado, las superficies se generan mediante variogramas, que no han ofrecido las garantía suficientes para representar un volumen de datos reducido y con una naturaleza desigual. Por ejemplo, los variogramas son muy sensibles a las variaciones bruscas entre las observaciones y acaban por demostrar casi en todos los casos la ausencia de un comportamiento espacial de las variables tipificado por uno de los modelos matemáticos que requieren. Aun así, no es descartable el uso de estos métodos en futuros trabajos.

Este tipo de exploraciones de la estructura de los datos puede ser un medio para acercarnos a la caracterización de los múltiples procesos que pueden conducir a la formación de las dispersiones de superficie. Éstos, como ya hemos visto, pueden ir desde la acumulación derivada de una actividad más o menos concentrada y duradera en el tiempo ("sitios" de muy diversa índole relacionados con la estructuración de los paisajes agrarios), hasta el fruto de prácticas reiteradas de carácter extensivo como el abonado. Al mismo tiempo, el llamado "ruido de fondo" puede corresponderse con diversos episodios en la explotación de la tierra, incluyendo el de la actividad

\begin{tabular}{|l|c|c|c|}
\hline & Tegula & Teja & $\begin{array}{c}\text { Torno } \\
\text { oxidante }\end{array}$ \\
\hline Tegula & 1 & $-0,46$ & 0,05 \\
Teja & $-0,46$ & 1 & 0,23 \\
Torno oxidante & 0,05 & 0,23 & 1 \\
\hline
\end{tabular}

Tab. 1. Matriz de correlación generada a partir de la correlación de los distintas superficies de tendencia generadas para la tegula, teja y cerámica oxidante realizada a torno. 

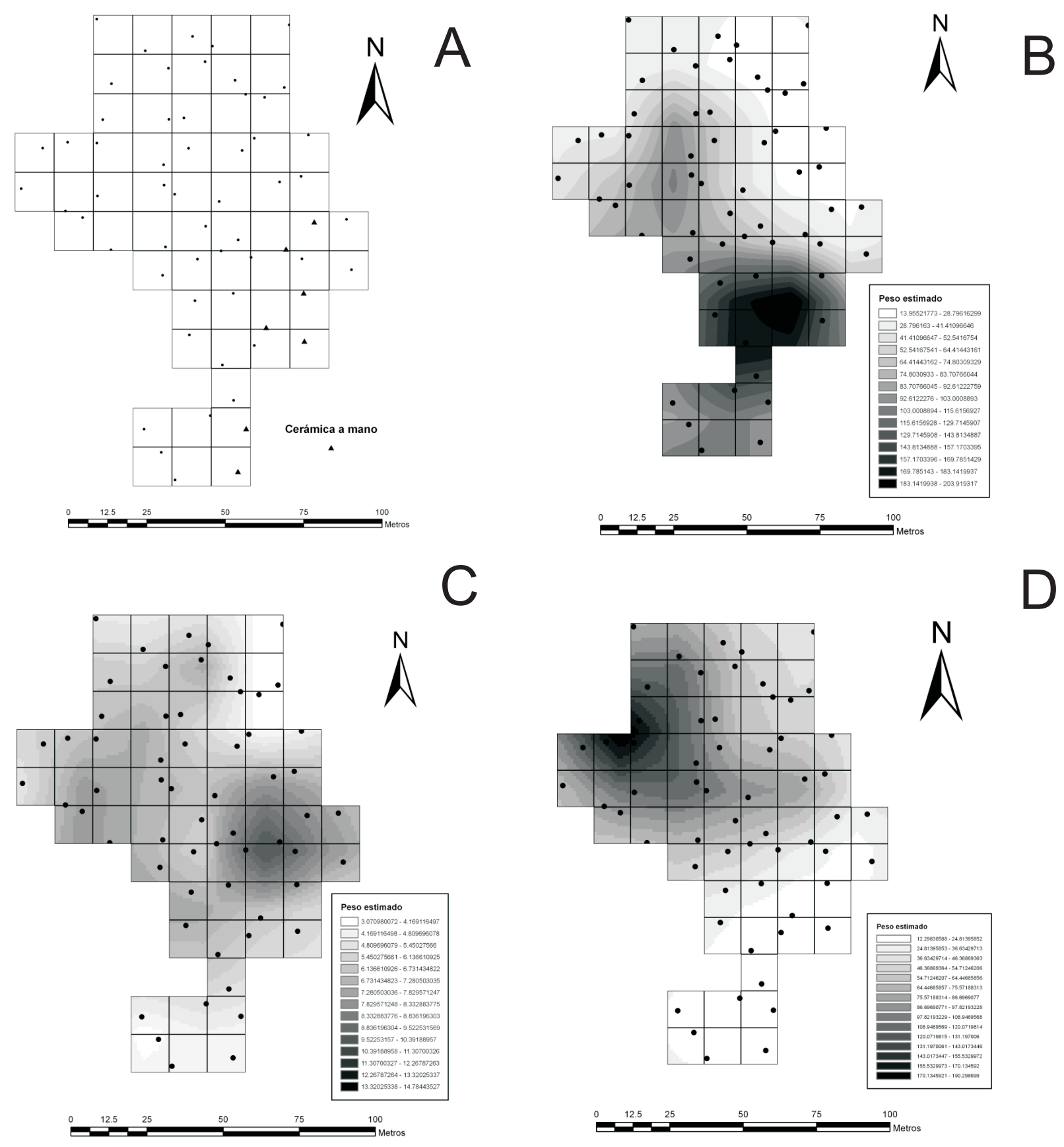

Fig. 10. Explorando una dispersión de superficie. A. Distribución de cerámica prehistórica "oculta” bajo una densa concentración de material romano. Superficie de Tendencia del peso estimado de B. Tegulas; C. Cerámica a torno oxidante; D. Teja árabe.

agrícola más reciente. En este último sentido una estrategia intensiva como la expuesta puede ser útil para calibrar la importancia de las alteraciones más modernas. Desde el punto de vista cronológico y funcional es igualmente interesante la posibilidad de establecer variaciones dentro de los conjuntos de superficie, valorando la existencia de cambios en la forma y tamaño de las ocupaciones a lo largo del tiempo o delimitando zonas de actividad. En cualquier caso, es importante 
avanzar hacia una caracterización más dinámica de las dispersiones, que tenga en cuenta factores relacionados con los procesos de alteración de los depósitos arqueológicos (Mayoral Herrera et al. 2006; Chapa Brunet et al. 2003). Un elemento clave para desarrollar esta aproximación sería un buen estudio geomorfológico del que aún no se dispone, dado el breve desarrollo temporal que tienen aún nuestros trabajos.

\section{PROBLEMAS Y PERSPECTIVAS FUTURAS}

Muchas cosas precisan ser mejoradas. Por lo que respecta al sistema de gestión de información durante el desarrollo del trabajo, es posible aumentar la agilidad y velocidad para descargar e integrar los recuentos iniciales. De cara a las próximas campañas de prospección se ha puesto a punto una aplicación basada en GRASS que realiza todo el proceso de descarga, almacenamiento, fusión y procesado de los datos de la primera fase del trabajo en un solo paso. Junto al ahorro de tiempo este sistema facilitará la gestión de un número mayor de receptores, lo cual puede multiplicar sensiblemente el ritmo de trabajo sin que ello afecte a la calidad de la información.

Otro problema aún no resuelto satisfactoriamente en cuanto a la ejecución de las prospecciones es la necesidad de adaptación a terrenos no cultivados en los que carecemos de una pauta para la inspección a intervalos regulares. La solución de trazar artificialmente los ejes de los recorridos no se considera satisfactoria, ya que el tiempo consumido en esta tarea es demasiado elevado en proporción al previsible rendimiento en cuanto a hallazgos en superficie. La alternativa que nos parece más viable sería cubrir estas zonas mediante puntos de muestreo, aunque la precisión exigida ralentizaría en cualquier caso el ritmo de trabajo. Por otra parte, el empleo de esta estrategia en zonas de escasa visibilidad presenta numerosos problemas en cuanto a la representatividad de los resultados (Banning 2002: 121). La cuestión tiene importancia, ya que concentrarse exclusivamente en los espacios cultivados introduce un claro sesgo en nuestra imagen de la huella humana en el paisaje. Debemos, por tanto, acometer de manera sistemática la exploración de sus zonas menos "amistosas" para la prospección.
En cuanto a los materiales recuperados, quizás los mayores problemas se refieren la adecuada clasificación cronológica de la cerámica, no sólo por la escasez de elementos con potencial valor diagnóstico, sino por la falta de referencias a escala regional para determinados períodos. Así, por ejemplo, es una difícil tarea diferenciar las cerámicas comunes de tradición local producidas durante los inicios de la presencia romana de las adscribibles a la etapa precedente. Otro problema para caracterizar las dispersiones es en ocasiones la superposición de un denso manto de material moderno. Hay que filtrar todo este "estruendoso" ruido para escuchar señales que se emiten con una frecuencia muy baja.

Tampoco tenemos respuestas sencillas para el tratamiento de una variable que estimamos importante, como es el desgaste y alteración del material de superficie. La escala utilizada se presta a una notable subjetividad, y sería preciso explorar el potencial de técnicas aplicadas en otros proyectos. En términos generales, pensamos que el estudio de esta cuestión podría abordarse desde una perspectiva experimental, confrontando muestras resultantes de la acción de procesos conocidos con los conjuntos arqueológicos. La tan debatida cuestión del abonado podría abordarse de esta manera, ya que aún subsisten en numerosas áreas rurales campos con claras evidencias de esta práctica tradicional e incluso el testimonio vivo de quienes las han mantenido.

$\mathrm{Si}$, finalmente, atendemos a la cuestión del análisis de los datos, su gran abundancia plantea tanto oportunidades como retos para lograr su adecuada explotación y valoración. Nos parece particularmente importante extremar el cuidado en la generación de la información que a su vez va a utilizarse como base para la realización de nuevos análisis. Esto se refiere tanto a las estimaciones preliminares sobre densidad de ítems como al sistema de muestreo (resolución de la malla, fracción muestral, tipo de unidad de muestreo...). En un plano más experimental, podemos señalar el potencial de la contraposición entre los recuentos globales y los resultados de los muestreos como una base interesante para la simulación de resultados, experimentando con el efecto que puede tener modificar los parámetros de estos últimos.

Para concluir, pensamos que el sistema de registro que hemos expuesto posee un gran potencial para el estudio intensivo del paisaje, tanto por 
la agilidad en su ejecución como por el volumen y calidad de la información que nos aporta. El proceso de trabajo es fluido en dos sentidos. Primero, por lo que respecta a la integración de sus diferentes etapas, permitiendo una rápida descarga y análisis de los datos de campo para a su vez retornar al terreno para realizar los muestreos. En segundo lugar, creemos que se ofrece un modus operandi que no plantea discontinuidad metodológica entre el estudio de las áreas de mayor concentración y las zonas de escasa o nula presencia de materiales en superficie. Esta consideración del sitio arqueológico como una entidad "anidada" en el paisaje es tributaria de la idea, apuntada en la introducción, de la importancia de una aproximación integradora al registro de la huella material en la totalidad del paisaje. Enlazando con nuestras reflexiones iniciales, lo que busca todo este desarrollo metodológico es, en última instancia, tender puentes entre el tratamiento intensivo de pequeñas áreas y el estudio a escalas más amplias. Es importante mantener esta perspectiva si nuestro objetivo es llegar a cuestiones sustantivas como la evolución demográfica, la intensidad de la explotación económica o la racionalidad de las decisiones de localización en el pasado. En definitiva, para acercarse a la lógica social de la estructuración de los paisajes agrarios a través del tiempo.

\section{AGRADECIMIENTOS}

Queremos en primer lugar expresar nuestra gratitud a Jose Ángel Salgado, Rebeca Cazorla, Ana Cabrera, Sergio Muñoz, M. ${ }^{a}$ Isabel Roger, Daniel Martín, Marcos A. Martelo, M. ${ }^{a}$ Jesús Domínguez, Rui Mataloto y Mario Gomes por su entusiasta colaboración en las tareas de prospección. Agradecemos a Antonio Uriarte, Teresa Chapa y Carlos Fernández sus impresiones y comentarios durante el proceso de elaboración de este texto.

\section{BIBLIOGRAFÍA}

Alcock, S.; Cherry, J.F. y Davis, J.L. 1994: "Intensive survey, agricultural practice and the classical landscape of Greece". En I. Morris (ed.): Classical Greece: Ancient Histories and Modern Archaeologies. Cambridge University Press. Cambridge: 137-169.

T. P., 66, N. ${ }^{\circ}$ 1, enero-junio 2009, pp. 7-25, ISSN: 0082-5638 doi: $10.3989 /$ tp.2009.09010
Banning, E.B. 2002: Archaeological Survey. Kluwer Academic/ Plenum Publishers. Nueva York.

Baxter, M.J.; Beardah, C.C. y Wright, R.V. 1997: "Some Archaeological Applications of Kernel Density Estimates". Journal of Archaeological Science 24: 347-354.

Bintliff, J.L. y Snodgrass, A.M. 1985: "The Cambridge/Bradford Boeotian Expedition: the First Four Years". Journal of Field Archaeology 12: 123-161.

Blanton, R.E. 2001: "Mediterranean myopia". Antiquity 75: 627-29.

Burillo, F.; Ibáñez, J. y Alegre, E. 2005: “Prospección y concepto de asentamiento. El caso de la ciudad celtibérica de Segeda". Arqueología Espacial 24-25: 165-184.

Campana, S. 2006: "DGPS e mobile GIS per l'archeologia dei paesaggi". En S. Campana y R. Francovich (eds.): Laser scanner e GPS: paesaggi archeologici e tecnologie digitali 1, atti del workshop, 3 marzo 2005 Grosseto. Edizioni all'Insegna del Giglio. Florencia: 201-225.

Celestino Pérez, S. 1996: El Palacio-Santuario de Cancho Roano V-VI-VII. Los sectores oeste, sur y este. Junta de Extremadura, publicaciones del Museo Arqueológico Provincial de Badajoz 3. Badajoz.

Celestino Pérez, S. (ed.) 2003: Cancho Roano VIII y IX. Los materiales arqueológicos. Instituto de Arqueología, CSIC. Mérida.

Celestino Pérez, S. y Jiménez Ávila, J. 1993: El Palacio-Santuario de Cancho Roano IV. El sector norte. Bartolomé Gil Santacruz. Badajoz.

Celestino Perez, S. y Walid, S. 2003: "Proyecto arqueológico "La Serena". En S. Torallas Tovar (ed.): Memoria. Seminarios de Filología e Historia. CSIC. Madrid: 47-53.

Chapa Brunet, T.; Uriarte González, A.; Vicent, J.M.; Mayoral Herrera, V. y Pereira Sieso, J. 2003: "Propuesta metodológica para una prospección arqueológica sistemática: el caso del Guadiana Menor (Jaén, España)". Trabajos de Prehistoria 60: 11-34.

Chapa Brunet, T.; Vicent, J.M.; Uriarte González, A.; Mayoral Herrera, V. y Pereira Sieso, J. 2004: "Un programa de prospecciones arqueológicas para el valle del Guadiana Menor (Jaén)". Arqueología Espacial 24-25: 123-144.

Foley, R. 1981: "Off-site archaeology: an alternative approach for the short-sited". En I. Hodder, N. Hammond y G. Isaac (eds.): Pattern of the Past: Essays in honour of David L. Clarke. Cambridge University Press. Cambridge: 157-183.

Gallant, T.W. 1986: "Background noise and site definition: a contribution to survey methodology". Journal of Field Archaeology 13: 403-418.

Gillings, M. 2000: "The utility of the GIS approach in the collection, management, storage and analysis of surface survey data". En J. Bintliff, M. Kuna y N. 
Venclova (eds.): The Future of Surface Artefact Survey. Sheffield University Press. Sheffield: 105120.

Gutiérrez, L.M.; Royo, M.Á.; Bellón, J.P. y Barba, V. 1998: "Microprospección de superficie en el entorno del monumento". En M. Molinos, T. Chapa, A. Ruiz, J. Pereira, C. Rísquez, A. Madrigal, A. Esteban, V. Mayoral y M. Llorente (eds.): El santuario heróico de El Pajarillo. Huelma. Universidad de Jaén. Jaén: 155-196.

Hayes, P.P. 1991: "Models for the distribution of pottery around former agricultural settlements". En A. Schofield (ed.): Interpreting Artefact Scatters. Contributions to Ploughzone Archaeology. Oxbow. Oxford: 81-92.

Keay, S.J.; Creighton, J. y Jordan, D. 1991: "Sampling Ancient Towns". Oxford Journal of Archaeology 10: 371-383.

Maluquer de Motes, J. 1981: El santuario protohistórico de Zalamea de la Serena (Badajoz) IV. 19781981. CSIC. Barcelona.

Maluquer de Motes, J. 1983: El santuario protohistórico de Zalamea de la Serena (Badajoz) V. 1981 1983. CSIC. Barcelona.

Mattingly, D. 2000: "Methods of collection, recording and quantification". En R. Francovich, H. Patterson y G. Barker (eds.): Extracting meaning from ploughsoil assemblages. The Archaeology of $\mathrm{Me}$ diterranean Landscapes. Oxbow books. Oxford: 5-15.

Mayoral Herrera, V.; Chapa Brunet, M.T.; Uriarte González, A. y Cabrera Díez, A. 2006: "Escuchando el ruido de fondo: estrategias para el estudio de los paisajes agrarios tardoibéricos en la región del Guadiana Menor". Arqueología espacial 26: 87-114.

Nieto Masot, A.; Hernández Carretero, A. y Leco Berrocal, F. 2003: "Metodología de prospección arqueológica mediante imágenes Landsat TM y Spot PAN en Zalamea de la Serena (Badajoz)". IX Con- ferencia Iberoamericana de Sistemas de Información Geográfica (Cáceres, 2003): CDRom.

Ortiz Romero, P. 1995: "De recintos, torres y fortines: Usos (y abusos)". Extremadura arqueológica 5: 177-194.

Rodríguez Díaz, A. y Ortiz Romero, P. 1998: “Culturas indígenas y romanización en Extremadura: castros, 'oppida' y recintos ciclópeos". En A. Rodríguez Díaz (ed.): Extremadura protohistórica: paleoambiente, economía y poblamiento. Universidad de Extremadura. Cáceres: 247-278.

Rodríguez Díaz, A. y Ortiz Romero, P. 2003: "Defensa y territorio en la Beturia: castros, oppida y recintos ciclópeos". En A. Morillo Cerdán, F. Cadiou y D. Hourcade (eds.): Defensa y territorio en Hispania de los Escipiones a Augusto (espacios urbanos y rurales, municipales y provinciales): coloquio celebrado en la Casa de Velázquez (19 y 20 de marzo de 2001). Universidad de León, Secretariado de Publicaciones y Medios Audiovisuales. Casa de Velázquez. Madrid-León: 219-252.

Rodríguez Díaz, A. y Ortiz Romero, P. 2004: "La torre de Hijovejo: génesis, evolución y contexto de un asentamiento fortificado en La Serena (Badajoz)". En P. Moret y T. Chapa Brunet (eds.): Torres, atalayas y casas fortificadas: explotación y control del territorio en Hispania (s. III a. de C.-s. I d. de C.). Universidad de Jaén. Jaén: 77-98.

Ruiz Zapatero, G. 2004: "La prospección arqueológica de superficie en los inicios del siglo XXI". Arqueología Espacial 24-25: 17-31.

Wheatley, D. y Gillings, M. 2002: Spatial Technology and Archaeology. The Archaeological Application of GIS. Taylor and Francis. Londres-Nueva York.

Wilkinson, T. 1982: "The Definition of Ancient Manured Zones by Means of Extensive Sherd-sampling Techniques". Journal of Field Archaeology 9: 323333.

Wilkinson, T. 1989: "Extensive sherd scatters and land-use intensity: some recent results". Journal of Field Archaeology 16: 31-46. 